\title{
Is Parkinson's Disease Acquired or Inherited?
}

\author{
Roger C. Duvoisin
}

\begin{abstract}
A considerable proportion of patients with Parkinson's disease report having affected relatives. However, anamnestic data obtained from probands on the occurrence of secondary cases among their relatives are of limited value. In considering the possible role of heredity in Parkinson's disease it is necessary to carefully distinguish between the disease and other disorders such as essential tremor and olivopontocerebellar atrophy which may manifest parkinsonian features. Controlled family studies have shown only a very slight excess of secondary cases among index siblings as compared to spouse siblings. The concordance rate for Parkinson's disease among identical twins is extraordinarily low and does not significantly exceed that among fraternal twins or that expected from the prevalence rate among siblings found in the controlled family studies. The available evidence indicates that heredity plays no significant role in the etiology of Parkinson's disease. Consequently the disease must be considered to be acquired.
\end{abstract}

RÉSUMÉ: Un grand nombre de Parkinsoniens indiquent qu'ils ont des parents atteints de la même maladie. Cependant les données historiques obtenues des probants sur les cas secondaires ne sont que d'une valeur limitée. En étudiant le rôle possible de l'hérédité dans la maladie de Parkinson il faut être en mesure de distingụer entre cette entité et des désordres tels le tremblement essentiel et la dégénérescence olivopontocérébelleuse. Des études contrôllées ont montré seulement un léger excès de cas secondaires parmi les frères et soeurs du cas index, comparés à la fratrie du conjoint. Le taux de concordance pour la maladie de Parkinson chez les jumeaux identiques est extraordinairement bas et ne dépasse pas le taux chez les jumeaux fraternels et celui dans les familles témoins. L'évidence disponible indique que l'hérédité ne joue pas un rôle significatif dans l'étiologie de la maladie de Parkinson. La maladie doit donc être considérée comme acquise.

Can. J. Neurol. Sci. 1984:11:151-155

Before reviewing the evidence available on the possible role of heredity in the etiology of Parkinson's disease, it is necessary first to consider the nosology and classification of parkinsonism or, to be more precise, the parkinsonisms. From a clinical perspective it has long been clear that parkinsonism is a syndrome of diverse etiology. Current knowledge of the anatomy, physiology and experimental pathology of the basal ganglia combined with post-mortem observations in various types of parkinsonism permit the view that it is a pathophysiologic state, its major motor manifestations reflecting degeneration or dysfunction of the dopaminergic nigrostriatal system. Various morbid processes can involve that system. The most common one encountered in medical practice today is the familiar morbid entity we know as Parkinson's disease. The clinical triad of resting tremor, bradykinesia and rigidity, particular abnormalities of posture, an insidious onset usually with tremor of one hand, slow progression from unilateral to generalized signs and symptoms are its halimarks. Lewy bodies are expected in the substantia nigra, locus ceruleus and other brain stem nuclei. Numerous other disorders of the central nervous system may involve the nigrostriatal neuronal system, usually as part of a more widespread process and consequently produce signs and symptoms similar to those of Parkinson's disease. Perusal of the classification of the parkinsonisms shown in Table I conveys some idea of their broad range.

Until the etiology of Parkinson's disease is discovered it will remain difficult to resolve doubts regarding its nosologic independence. Nevertheless, combined clinical and pathological considerations justify the conclusion that it is a particular

\section{Table 1: A Classification of the Parkinsonisms}

1. Parkinson's disease
a. Classic Lewy body disease
b. With Alzheimerization
c. Juvenile onset

2. Post-encephalitic

a. Encephalitis lethargica

b. Other encephalitides

c. Luetic mesencephalitis

3. Iatrogenic

4. Symptomatic

a. Structural lesions - congenital, acquired, neoplastic

b. Postraumatic

c. Toxic - metabolic

5. Multiple System Degeneration

Strio-nigral degeneration

The Olivopontocerebellar atrophies

Progressive Supranuclear Palsy

The Shy-Drager Syndrome

Wilson's disease

Hallervorden-Spatz disease

Creutzfeld-Jakob disease

Phenotypic variants of various genetic disorders

Parkinson-dementia complex

Pallido-nigral degeneration

6. Pseudo Parkinsonism

Multiple cerebral infarctions

Normal pressure hydrocephalus

Acquired hepatocerebral degeneration 
morbid entity which may be presumed to have a specific though as yet unknown etiology and pathogenesis. The recognition of distinct disorders such as strionigral degeneration (SND), and Progressive Supranuclear Palsy (PSP) and the growing recognition of olivopontocerebellar atrophy (OPCA) with parkinsonian features in the past two decades have placed Parkinson's disease in sharper relief.

Some of the limits of Parkinson's disease remain admittedly somewhat fuzzy. For example, the occurrence of organic dementia of the Alzheimer type, signs of pyramidal tract involvement, dysautonomia, or dystonic manifestations pose conceptual difficulties.

It may on occasion be difficult to classify precisely a given patient, at least early in the clinical course. Indeed, a small proportion of patients assigned the diagnosis of Parkinson's disease by experienced clinicians prove subsequently after several years' observations or on post-mortem examination, to have another disorder. Cases of unusually early onset, especially onset under age 20 (Juvenile Parkinsonism) pose particular diagnostic difficulties. Onset under age $\mathbf{4 0}$ has been found in many studies to be exceedingly uncommon (Hoehn, 1976). Some juvenile cases are probably bona fide examples of Parkinson's disease such as the case recently described by Clough, et al. (1981) but most are not. Juvenile Parkinsonism represents a very heterogenous group of rare predominantly genetic disease such as Wilson's disease, Hallervorden-Spatz disease, olivopontocerebellar atrophy, variants of spinocerebellar degeneration, unusual phenotypes of the lipidoses and other as yet ill-defined diseases. Although the proportion is small, the inclusion of such patients in a genetic study may seriously contaminate the data. This is especially likely to occur with OPCA cases. Although manifestations of cerebellar dysfunction e.g., ataxic gait, pes cavus and dysarthria in a parkinsonian patient producing what we may call the syndrome of "cerebellar parkinsonism " is characteristic of the OPCA's, occasional patients with OPCA may present only parkinsonian features and may for several years in the evolution of their condition be difficult to distinguish clinically from Parkinson's disease. Since some of the OPCA's are dominantly inherited, such a patient may have a strong positive family history. It appears likely that kindreds of "parkinsonism" such as those reported by Allen (1927) Bell and Clark (1926) and Spellman (1962), represent families of OPCA.

Uncertainty regarding the relationship of essential tremor to Parkinson's disease has been an important source of confusion in family studies of Parkinson's disease. Gowers (1893) had remarked that "non-progressive tremor occasionally exists throughout life in some near relation". As Larsen and Calne note in their recent review (1983) it has often been misdiagnosed as Parkinson's disease. The occasional occurrence of both conditions in the same individual has suggested to some that essential tremor is a "forme fruste" of Parkinson's disease (Critchley, 1949). However, essential tremor is a fairly common condition; with a prevalence of at least $410 / 100,000$ (Haerer et al., 1982), several times greater than that of Parkinson's disease. Much higher prevalence rates were found by Larsson and Sjogren (1960) and by Rautakori et al. (1978). One might thus expect the occasional occurrence of both conditions together by chance alone. Moreover, if essential tremor were in fact a "forme fruste" of Parkinson's disease, then one would expect to find the latter in families of essential tremor with some frequency, but such is not the case. Neither Larsson and Sjogren (1960) nor Rautakorpi in a more recent study (1978) found any cases of Parkinson's disease among the families of essential tremor they studied.

Clinical surveys of Parkinson patients undertaken in search of evidence on the presumed role of heredity are hampered by the fact that the diagnosis of Parkinson's disease and its differentiation from other similar disorders rests entirely on clinical judgment. There is no chemical or serological marker, no unique or pathognomic sign and no diagnostic laboratory test. Yet careful differentiation of Parkinson's disease from other disorders resembling it is crucial to a reasonable assessment of the evidence presented for and against the hypothesis of a significant genetic contribution. Failure to make such distinctions, whether due to methodologic deficiencies or conceptual bias has long confused the subject. Grouping together diverse entities such as essential tremor, OPCA, PSP, SND, some genetic and others non-genetic, under a common rubric leads to a composite estimate of heritability for a heterogenous group. The possibility of diagnostic error can be reduced though not fully eliminated by adhering to strict criteria consistently applied and wherever possible, making use of control populations.

\section{Familial Concentration}

The notion that heredity plays a role in the etiology of Parkinson's disease derived initially from the common clinical experience that occasional patients report having one or more relatives with a "similar" condition. For example, Gowers (1903) had noted that $15 \%$ of his 123 patients gave a positive family history. Hart (1904) and other early students of the disorder noted similar frequencies of positive family histories; more recently Kurland et al. (1958) and Hoehn (1976) reported frequencies of $16 \%$ and $19 \%$ respectively. Roy et al. (1982) elicited positive family histories in 50 of 643 patients plus a number of newly referenced cases.

What is the significance of the frequency with which patients with Parkinson's disease report having similarly affected relatives? It is difficult to judge whether it does in fact represent familial concentration in view of the relative prevalence of parkinsonism, its chronicity and the common misdiagnosis of essential tremor as parkinsonism. Moreover, these secondary cases may represent remote as well as immediate relatives and it is extremely difficult to ascertain the magnitude of the population at risk.

In an effort to obtain some additional information on positive family histories, Wieder and I examined the records of 207 patients with typical Parkinson's disease culled from my private consulting practice. A positive family history of parkinsonism or tremor had been elicited in $47(23 \%)$ of my patients. If affected relatives reported to have had tremor alone, were excluded, then only $37(17.9 \%)$ of the patients gave a positive family history. The secondary cases comprised 15 parents, 11 siblings, 12 parent-siblings (i.e. aunts or uncles), 6 cousins and 3 grandparents; thus nearly half were not immediate relatives.

It was not possible to ascertain the total number of aunts, uncles and cousins at risk or even to gain any knowledge of their fate. However, there were 414 parents and 590 siblings at risk. The proportion of affected parents $-3.6 \%$ was significantly greater than the proportion of affected siblings (1.9\%). The parents, however, represented an older age group whereas many of the siblings had not yet reached the ages of highest 
risk. Interestingly, the proportion of secondary cases among the siblings of patients reporting an affected parent (1/41) was not significantly different from the proportion among the siblings of all the other patients (10/529).

It would have been interesting to compare the prevalence of Parkinson's disease among the patient siblings with that which might be predicted from the prevalence rates documented in population studies such as those of Kurland et al. (1958), Kessler (1978) and Rajput (1983). However, since the methods of ascertainment are very different, a direct comparison cannot be made. The population surveys count the number of cases in a defined population on a particular day, a finite point in time. The secondary cases identified anamnestically from patients' histories are counted over a very long period of time; indeed, many were long deceased. A more appropriate comparison would be the life-time probability of any one individual randomly selected in the population developing Parkinson's disease. From his population survey of Rochester, Minnesota, Kurland calculated that one individual in forty would develop parkinsonism at some time. Thus, one might expect that $2.5 \%$ of any population at risk should presently be affected, should have been affected if deceased, or will be affected in the future. The proportion of parents affected, nearly all of whom were deceased, is surprisingly close to that figure. The proportion of siblings affected is somewhat less, as might be expected since not all of these have reached the ages of highest risk. However, it is impossible to say whether these differences are statistically significant. Even if they are, the differences are remarkably small, and these observations do not support the hypothesis of a significant genetic factor in Parkinson's disease.

A number of family studies of this type have been published. Perhaps the first one of note was that of Scarpalezos (1948) who reviewed the records of parkinsonian patients hospitalized at the Salpetriere and Bicetre hospitals in Paris in the years 1922-1948. He found 7 patients amongst 262 classified as idiopathic parkinsonism who gave a positive family history - an incidence of $3 \%$. However, details provided by this author indicate that at least 2 of his probands had essential tremor and 1 post-encephalitic parkinsonism, leaving only 4 of 262 cases of Parkinson's disease with secondary cases.

\section{Mjones' Study}

Mjones carried out the first major genetic analysis of parkinsonism. His extensive and detailed study exerted considerable influence on thinking on this subject and warrants careful consideration. He culled from the records of 9 neurological clinics in Sweden 250 cases of parkinsonism after excluding, as far as possible, post-encephalitic cases and made a field investigation of the families in which the proband was classified as Paralysis agitans, arteriosclerotic parkinsonism or "Parkinsonism" according to carefully stated criteria. For secondary cases, however, different diagnostic criteria were used. Although he excluded probands with "hereditary tremor" or with tremor alone in the absence of any other extrapyramidal feature, he counted relatives with long-standing tremor alone as secondary cases of "Paralysis agitans". One of these had only tremor of the voice, another only head tremor. Many had had tremor of the hands ten or more years with no other findings and no disability. Mere relationship to the index case was considered a "diagnostic indication" for "without this factor a number of abortive or incipient secondary cases would undoubtedly have been interpreted as, for example, essential tremor". On this bases, Mjones found 162 secondary cases among the relatives of $79(40.7 \%)$ of the 194 probands classified as Paralysis agitans and concluded that the disease was an autosomal dominant with $60 \%$ penetrance. Unfortunately it is not possible to assess the degree of familial concentration suggested by this data because the size of the population considered; that is, the total number of relatives, is not known. However, this can be done if the data can be tabulated separately for various degrees of kinship, e.g., siblings, and if the number of family members in each group is specified. Fortunately, he presented his data in sufficient detail to permit tabulation of the secondary cases among parents and siblings though not for other relatives (Table 2 [A]). It turns out that $46 / 388(11.9 \%$ ) of the parents and $50 / 694$ (7.2\%) of adult siblings over 20 years of age were affected.

Mjone's argument that in regard to mild neurological manifestations "there is no other reasonable explanation than an intimate genetic connection with Parkinson's disease" and his practice of counting oligosymptomatic cases as secondary constitutes, in effect, circular reasoning; i.e., the existence of secondary cases is the proof of heredity and the cases must be secondary because genetic theory so requires. Whether the inclusion of oligosymptomatic cases with solitary tremor is justified is impossible to determine from his data. This is a crucial point upon which turns the major conclusion of this otherwise excellent study.

Two epidemiological considerations suggest that it is not. First, if these cases, in fact, represented a "forme fruste" of the disease as he believed, then the onset of symptoms should have occurred at the same age or perhaps a bit later. However, Mjones' data is just the reverse: the age of onset in the secondary cases was about 10 years earlier on average. Second, Parkinson's disease should be found in appreciable incidence among families of essential tremor, in which it occurs in a simple dominant pattern. Yet as noted above, large population surveys of essential tremor have not found any cases of Parkinsonism in the families of essential tremor studied.

If one recalculates Mjones' data using as far as possible, the same criteria for secondary cases as for probands, omitting doubtful diagnoses and eliminating cases with solitary tremor, then the number of secondary cases fall sharply as shown in Table 2 [B] to 21 of 674 siblings. Thus this data do not indicate a significant familial concentration.

A control series with which comparisons could be made would have made it possible to assess the relevance - if any of mild or solitary manifestations such as tremor and the significance of the affected proband siblings. The family study carried out by Duvoisin et al. (1969), employed spouses and spouse siblings as a control population for this purpose. All spouses and siblings were examined by the same research team in a standardized manner. The prevalence of secondary cases among

Table 2: Data on secondary cases among index siblings from Mjones (1949), as originally presented (A) and recalculated to exclude cases with tremor only (B)

\begin{tabular}{|c|c|c|c|}
\hline \multirow[b]{3}{*}{ A. Separate Criteria } & \multicolumn{2}{|c|}{$\begin{array}{c}\text { Siblings } \\
\text { of Index Cases }\end{array}$} & \multirow[b]{2}{*}{$\underline{\%}$} \\
\hline & No. at Risk & No. Affected & \\
\hline & 694 & 50 & $7 . \overline{2} \%$ \\
\hline B. Uniform Criteria & 674 & 21 & $3.1 \%$ \\
\hline
\end{tabular}


Table 3: Prevalence of secondary cases of Parkinson's disease among probands siblings and spouse siblings in the three family studies cited

\begin{tabular}{|c|c|c|c|c|c|}
\hline Mjones $(1949)^{*}$ & 194 & $21 / 674$ & - & $19 / 404$ & - \\
\hline Duvoisin et al. (1968) & 85 & $4 / 146$ & $3 / 145$ & $4 / 62$ & $3 / 62$ \\
\hline Martin et al. (1973) & 130 & $16 / 488$ & $7 / 450$ & $11 / 285$ & $5 / 194$ \\
\hline
\end{tabular}

*The data from Mjones has been recalculated as described to exclude monosymptomatic cases.

the adult siblings of 85 patients diagnosed as Parkinson's disease was compared to that among the spouse siblings. An equal number $(5)$ of individuals with tremor alone were encountered in the two groups. Secondary cases of parkinsonism were found in 4 of 146 patient siblings and in 3 of 145 spouse siblings (Table 3 ). If the tremor cases are combined with the secondary cases of parkinsonism to replicate Mjones' handling of the data, the apparent prevalence of secondary cases rises to $9 / 146(6.2 \%)$ among the patient siblings, a proportion similar to that reported by Mjones and to $8 / 145$ among the spouse siblings. These data serve to explain Mjones' interpretation and to justify the recalculation of his data as described above. The data from the control series also indicated that there was no significant familial concentration of Parkinson's disease nor an association of essential tremor with Parkinson's disease.

A very similar family study was performed by Martin et al. (1973). The data are very similar to that reported by Duvoisin et al. The prevalence of secondary cases among the proband siblings ( $16 / 488$ or $3.3 \%$ ) was only very slightly greater than that among the spouse siblings (7/450 or $1.5 \%$ ). All three family studies yielded nearly identical data: the proportion of siblings affected is $2.5 \%$ in Mjones' (recalculated) study; $2.7 \%$ in the study of Duvoisin et al., and $3.3 \%$ in the study of Martin et al. Thus the three major family studies of Parkinson's disease on record have failed to document any significant family concentration and consequently provide no evidence for a significant genetic contribution.

Martin et al. noted that 15 of their probands reported an affected parent - these 15 probands had 77 siblings, 10 of whom were affected. In order to obtain sufficient numbers to calculate heritability, these authors culled 11 similar families from Mjones' paper and using this pooled data calculated by Falconer's (1965) method a value for heritability of $40 \pm 11 \%$. This data, however, is weakened by the fact that the allegedly affected parents were not personally examined but diagnosed by history, a potentially grievous defect in view of the common misdiagnosis of essential tremor and senile tremor as parkinsonism and because multiple-case families are likely to represent OPCA. In my personal experience, examination of parents reported to have parkinsonism reveals another diagnosis in at least one half. Thus even the rather modest estimate of $40 \%$ heritability must be regarded with some skepticism.

Recently, Roy et al. (1983) reported 50 "familial cases" of parkinsonism uncovered on screening 643 Parkinson patients followed at the Montreal Clinical Research Center plus a "certain number of referred new cases". Since the number of "new cases" is not specified the proportion of their patients provid- ing positive family histories cannot be precisely determined, however, it cannot be more than $50 / 643$ or $7.8 \%$, a much lower proportion than others have noted. The $\mathbf{5 0}$ families comprised 12 with secondary cases of parkinsonism, 28 with secondary cases of essential tremor and 10 with both secondary cases of parkinsonism and secondary cases of essential tremor. These authors indicate that there were 30 secondary cases of parkinsonism; 19 (2.9\%) among 648 first degree relatives (parents, children and siblings) and 11 among the 2550 more remote family members. Further subdivision of the data is not provided so that a precise count of the prevalence of secondary cases among siblings or among parents is not possible. The overall prevalence among first degree relatives of $2.9 \%$ is, however, very similar to that in the family studies discussed above (Table 3) and does not suggest a familial concentration of parkinsonism in their patient population.

Roy et al. consider their 28 patients who had relatives with essential tremor as having familial parkinsonism. An example of such a kindred offered in illustration shows a grandparent, a great uncle and one of three sons affected with essential tremor. Although this appears reminescent of Mjones' handling of secondary cases of essential tremor, the authors believe that these cases represent a syndrome of dominantly inherited "tremorrelated" parkinsonism, previously described by Barbeau et al. (1982). They also identify a recessively-inherited "akinetorigid" syndrome appearing in several families with 2 or more cases of parkinsonism. Although the title of their paper refers to familial "Parkinson's disease", they conclude that these two syndromes probably represent new disorders distinct from "idiopathic parkinsonism'. In addition, 2 of their families were thought to have other disorders "mimicking Parkinson's disease", the index cases representing phenocopies of Parkinson's disease.

Whether a separate identification of a type of parkinsonism associated with essential tremor is justified must await further study. In the meantime, these interesting observations may serve to emphasize the difficulty of excluding some small degree of genetic predisposition by family studies alone. A family study of such enormous size would be required that it would be impractical. Furthermore, a problem with family studies is that because of the late onset of Parkinson's disease, the parents are seldom available for examination and the children of patients are too young to be at significant risk. As Kondo, et al. (1973) suggested, a study of twins is the most economical and direct means of assessing the role of genetic factors in a disorder of reasonable prevalence.

With these goals in mind, the author and several collaborators initiated several years ago a survey of patients with 
Parkinson's disease who were members of twin pairs. Emphasis was placed on ascertaining monozygotic twins. Monozygosity was established by appropriate genotyping procedures. All twin pairs were personally examined by the investigators. Zero concordance was found in the first 12 consecutively examined twin pairs (Duvoisin, et al., 1981). The study was subsequently expanded to include a total of 43 monozygotic twins, and 20 dizygotic twin pairs in which the proband was believed to have Parkinson's disease (Ward et al., 1983). Great care was taken to assure consistent and uniform diagnosis. The subjects of the study included a set of quadruplets, 3 of whom were monozygotic. The major finding was that only 2 of the 43 monozygotic twin pairs were concordant, one of these being doubtful, and that of the 20 dizygotic twin pairs, only 1 was concordant. Clearly the monozygotic concordance does not exceed the dizygotic concordance and the null hypothesis that genetic factors play no role in the etiology of Parkinson's disease is verified. The difference is not significant at $\mathrm{p}<0.01$.

The number of dizygotic twins is not as large as one would wish. However, one can assume that the dizygotic concordance rate should be the same as the prevalence among all siblings. Thus the proportion of affected siblings documented in the major family studies cited above - approximately $3 \%-$ may be substituted for the dizygotic concordance for a stricter test. If genetic factors play a role, then monozygotic concordance should significantly exceed $3 \%$, but the highest monozygotic concordance we can obtain from the twin study is $2 / 43$ or $4.7 \%$. We may thus conclude that the role of genetic factors in the etiology of Parkinson's disease is negligible and consequently that the disease is acquired.

The negative conclusion applies only to Parkinson's disease and not to other disorders resembling it and which may be considered forms of parkinsonism, nor to the various hereditary disorders which may on occasion produce at least approximate phenocopies of Parkinson's disease. Genetic factors may play a role in some forms of parkinsonism but these comprise a heterogenous group accounting for only a small proportion of the full clinical spectrum of parkinsonism. The major form of parkinsonism - Parkinson's disease - appears almost certainly to be an acquired disease. Reported differences in the prevalence of parkinsonism in different ethnic populations (Rosati et al., 1980) may represent clues to an environmental etiologic agent rather than evidence of a genetic factor. Further epidemiologic studies will hopefully provide some helpful clues to environmental factors which may be significant in the etiology of Parkinson's disease.

\section{REFERENCES}

Allan W (1927) Inheritance of the Shaking Palsy. Arch. Int. Med. 60: 424-436.
Barbeau A, Pourcher E (1982) New data on the genetics of Parkinson's disease. Can. J. Neurol. Sci. 4: 53-60.

Bell J, Clark AJ (1926) A Pedigree of Paralysis Agitans. Ann. Eugen. I: 445-462.

Clough CG, Mendoza M, Yahr MD (1981) A Case of Sporadic Juvenile Parkinson's Disease. Arch. Neurol. 38: 730-731.

Critchley M (1949) Observations on essential (heredofamilial) tremor. Brain 72: 113-139.

Duvoisin RC, Gearing FR, Schweitzer MD, Yahr MD (1969) A Family Study of Parkinsonism. In: A. Barbeau and J.R. Brunette, eds. Progress inNeurogenetics. Amsterdam, Excerpta Medica, pp. 492-496.

Duvoisin RC, Eldridge R, William A, Nutt J, Calne DB (1981) Twin Study of Parkinson Disease. Neurology 31: 77-80.

Falconer DS (1965) The inheritance of liability to certain diseases estimated from the incidence among relatives. Ann. Human Genet. 29: $51-76$.

Hearer AF, Anderson UW, Schoenberg BS (1982) Prevalence of essential tremor. Arch. Neurol. 39: 750-752.

Hart TS (1904) Paralysis Agitans: Some clinical observations based on the study of 219 cases at the clinic of Professor M. Allen Starr. J. Nerv. Ment. Dis. 31: 177-178.

Hoehn MM (1976) Age distribution of patients with parkinsonism. J. Am. Ger. Soc. 24: 79-85.

Kessler II (1978) Parkinson's disease in epidemiological perspective. Adv. Neurology. 19: 355-383.

Kondo K, Kurland LT, Schull WJ (1973) Parkinson's disease, genetic analysis and evidence of a multi-factorial etiology. Mayo Clin. Proc. 48:465-475.

Kurland LT (1958) Epidemiology: Incidence. Geographic Distribution and Genetic Consideration. In: W. Fields, ed. Parhogenesis and Treatment of Parkinsonism. Springfield, Chas. C. Thomas. pp. 5-49.

Larsen TA, Calne DB (1983) Essential Tremor. Clin. Neuropharmacol. 6: $184-206$.

Larsson T, Sjogren T (1960). Essential Tremor: A Clinical and Genetic Population Study. Acta Psychiatria Scand. 36, Supp. 144: 1-176.

Mjones H (1949) Paralysis Agitans. A Clinical Genetic Study. Acta Psychiat. et Neurol. Scand. 25, Suppl. 54: 1-195.

Martin WE, Young WI, Anderson VE (1973). Parkinson's Disease, A Genetic Study. Brain 96: 495-506.

Rajput AJ, Elveback LR, Beard CM, Kurland LT (1981). Epidemiology of Parkinson's disease in Rochester, Minnesota. Paper presented at 12th World Congress for Neurology, Kyoto. Japan. Sept. 1981. International Congress Series 548, Amsterdam, Excerpta Medical. Abstract 47.

Rautakorpi I, Takala J, Marttila RJ, Sievers K, Rinne VK (1978) Essential tremor in a Finnish population. Acta Neurol. Scand. 66: 58-67.

Rosati G, Granieri E, Pinna L., Aiello I, Tola R et al. (1980) The risk of Parkinson disease in Mediterranean people. Neurology 30: 250-255.

Roy M, Boyer L, Barbeau A (1983) A study of 50 cases of familial Parkinson's disease. Can. J. Neurol. Sci. 10: 37-42.

Scarpalezos S (1948) Sur la notion d'heredite similaire dans la maladie de Parkinson. Rev. Neurologique 80: 184-203.

Spellman GG (1962) Report of familial cases of parkinsonism. J. Am. Med. Assoc. 179: 160-162.

Ward CD, Duvoisin RC, Ince SE, Nutt JD, Eldridge R, Calne DB (1983) Parkinson's disease in 65 pairs of twins and in a set of quadruplets. Neurology 33: 815-824. 